\title{
Effects of Iron Concentration Level in Extracting Solutions from Contaminated Soils on the Determination of Zinc by Flame Atomic Absorption Spectrometry with Two Background Correctors
}

\author{
Christophe Waterlot, ${ }^{1,2}$ Aurélie Pelfrêne, ${ }^{1,2}$ and Francis Douay ${ }^{1,2}$ \\ ${ }^{1}$ Université Lille Nord de France, 59044 Lille, France \\ ${ }^{2}$ Groupe ISA, Equipe Sols et Environnement, Laboratoire Génie Civil et géo-Environnement (LGCgE) Lille, Nord de France (EA 4515), \\ 48 boulevard Vauban, 59046 Lille Cedex, France \\ Correspondence should be addressed to Christophe Waterlot, christophe.waterlot@isa-lille.fr
}

Received 8 November 2011; Accepted 10 December 2011

Academic Editor: K. K. Verma

Copyright (C) 2012 Christophe Waterlot et al. This is an open access article distributed under the Creative Commons Attribution License, which permits unrestricted use, distribution, and reproduction in any medium, provided the original work is properly cited.

\begin{abstract}
Zinc and iron concentrations were determined after digestion, water, and three-step sequential extractions of contaminated soils. Analyses were carried out using flame absorption spectrometry with two background correctors: a deuterium lamp used as the continuum light source $\left(\mathrm{D}_{2}\right.$ method) and the high-speed self-reversal method (HSSR method). Regarding the preliminary results obtained with synthetic solutions, the $\mathrm{D}_{2}$ method often emerged as an unsuitable configuration for compensating iron spectral interferences. In contrast, the HSSR method appeared as a convenient and powerful configuration and was tested for the determination of zinc in contaminated soils containing high amounts of iron. Simple, fast, and interference-free method, the HSSR method allows zinc determination at the ppb level in the presence of large amounts of iron with high stability, sensitivity, and reproducibility of results. Therefore, the HSSR method is described here as a promising approach for monitoring zinc concentrations in various iron-containing samples without any pretreatment.
\end{abstract}

\section{Introduction}

Flame atomic absorption spectrometry (FAAS) is often described as a fast, simple, and sensitive technique for the measurement of zinc $(\mathrm{Zn})$. This technique is widely used for the determination of $\mathrm{Zn}$ at trace levels in biological samples and food after mineralization process [1-4], but it usually requires pretreatment of samples such as sorption and/or preconcentration [5, 6], coprecipitation [7-9], liquid-liquid extraction $[9,10]$, solid-phase extraction [9-15], and more recently cloud point extraction $[16,17]$ in order to eliminate the matrix effects. However, these methods usually suffer from a lack of automation, increasing greatly the handling effort. Many research efforts have recently focused on a minimally time-consuming sample pretreatment, and consequently flow injection analysis (FIA) systems have been developed for the determination of $\mathrm{Zn}$ using FAAS [18-20]. Despite of these attempts, it is worth noting that the digestion process of soil samples is needed to convert them into solutions to be introduced through nebulization chambers of the FAAS.

Of the two atomic absorption lines of $\mathrm{Zn}$, at 213.856 and $307.950 \mathrm{~nm}$, the latter is hardly used for trace $\mathrm{Zn}$ analysis in FAAS because its sensitivity is 3,000 times lower than the former. Because this analytical line is subjected to spectral interferences by line overlapping at $213.859 \mathrm{~nm}$ and $213.853 \mathrm{~nm}$ due to the presence of $\mathrm{Fe}$ and $\mathrm{Cu}$, respectively $[21,22]$, the determination of $\mathrm{Zn}$ at trace levels in the presence of $\mathrm{Fe}$ and/or $\mathrm{Cu}$ may be difficult with FAAS. For instance, the iron line at $213.859 \mathrm{~nm}$ cannot be completely resolved from the zinc resonance line at $213.856 \mathrm{~nm}$ by the optical system, resulting in a spectral interference using the conventional FAAS, without or with background correction, like deuterium lamp or Zeeman effect [23]. According to our knowledge, only the combination of the high-resolution 
continuum-source atomic absorption spectrometry with the least-squares background correction is able to resolve completely the problem of spectral interferences by direct overlap of absorption lines such as Fe and $\mathrm{Zn}[22,23]$.

While very few studies have focused on the elimination of Fe in the determination of Zn using FAAS [24-27], the determination of $\mathrm{Zn}$ concentrations within the extracting solutions from contaminated soils without any pretreatment using FAAS is poorly documented, probably due to the low level of Fe and $\mathrm{Cu}$ matrix and the high level of $\mathrm{Zn}$. Therefore, the present study focused on the use of a self-reversal background corrector. A first approach of the method has been proposed in 1983 by Smith and Hieftje [28]. A second approach has been recently developed and was called highspeed self-reversal method (HSSR method) [29]. This method was described as a universal technique covering the entire wavelength range from 190 to $900 \mathrm{~nm}$. Based on previous studies in which it was shown that $\mathrm{Cu}$ concentrations were much lower than $\mathrm{Zn}$ within the contaminated soils located in the studied area $[28,29]$, the present work focused on the determination of $\mathrm{Zn}$ in extracting solutions containing high Fe concentrations using FAAS combined with the HSSR method. Results were compared with those obtained with the deuterium lamp used as the continuum-source background corrector ( $\mathrm{D}_{2}$ method). A systematic study was first conducted in spiked $\mathrm{Zn}$ solutions with low and high Fe concentrations in order to handle spectral interferences and matrix effects when the mobility of $\mathrm{Zn}$ in contaminated soils was examined. The method was then used to detect $\mathrm{Zn}$ concentrations extracted by water and aqua regia in certified reference materials and in contaminated soils, focusing on the possible overlapping analytical line of $\mathrm{Zn}$ at $213.856 \mathrm{~nm}$ with NO molecular absorption bands in the air-acetylene flame. The HSSR method was then validated using the first three steps of the sequential extraction procedure recommended by the SM\&T (standards, measurements, and testing program) using two certified reference materials and contaminated soil samples.

\section{Materials and Methods}

2.1. Standard Solutions and Reagents. All solutions were prepared from analytical-grade reagents unless otherwise specified. Doubly distilled water (Carlo Erba, Val de Reuil, France) was used to prepare all aqueous solutions and dilutions.

(i) Glacial acetic acid (Acrōs Organics, Noisy-le-Grand, France, $d=1.048$ ) was used to obtain the $0.11 \mathrm{M}$ acetic acid.

(ii) $0.5 \mathrm{M}$ hydroxylamine hydrochloride was prepared by dissolving $34.75 \mathrm{~g}$ of the solid (Acrōs Organics) in $975 \mathrm{~mL}$ of doubly distilled water after adding $25 \mathrm{~mL}$ of $2 \mathrm{M}$ nitric acid $\left(\mathrm{HNO}_{3}\right)$, prepared by diluting $12.7 \mathrm{~mL}$ of $\mathrm{HNO}_{3}$ (J.T. Baker for metal trace analysis, Deventer, Netherlands, $70 \%, d=1.42$ ) to $100 \mathrm{~mL}$ in a volumetric flask.

(iii) $1 \mathrm{M}$ ammonium acetate solution was obtained by adding $77.08 \mathrm{~g}$ of the solid in $1000 \mathrm{~mL}$ of doubly distilled water after adjusting the $\mathrm{pH}(\mathrm{pH}=2)$ with $65 \% \mathrm{HNO}_{3}(d=1.40)$.

(iv) Hydrogen peroxide was from J.T. Baker.

(v) Aqua regia was obtained by mixing concentrated $4.5 \mathrm{~mL}$ of hydrochloric acid (J.T. Baker, 37\%, $d=$ $1.19)$ and $1.5 \mathrm{~mL}$ of $\mathrm{HNO}_{3}(70 \%)$.

All glassware and polypropylene materials were cleaned by soaking for 1 day in $0.5 \mathrm{M}$ nitric acid (J.T. Baker) and by rinsing with doubly distilled water. Zinc solutions of 1, 2, and $5 \mathrm{mg} \mathrm{L}^{-1}$ in $2 \% \mathrm{HNO}_{3}$ (Chemical Products for Analysis, Association Corporation Standard Distribution; C.P.A. groupe A.C.S.D., Voisins le Bretonneux, France) were used for the preparation of the calibration solutions and test solutions containing Fe.

2.2. Instrumentation. An atomic absorption spectrometer (Shimadzu AA-6800, Tokyo, Japan) with an ASC-6100 autosampler (Shimadzu) was used for the determination of Fe and $\mathrm{Zn}$ with an air-acetylene flame. For Fe, the instrumental parameters were as follows: wavelength $248.3 \mathrm{~nm}$; lamp current $12 \mathrm{~mA}$; bandpass $0.2 \mathrm{~nm}$; a deuterium lamp (Hamamatsu, Photonics K.K., Tokyo, Japan) for the background correction. For $\mathrm{Zn}$, a conventional hollow-cathode lamp from Hamamatsu was used at $213.856 \mathrm{~nm}$ with a $0.5-\mathrm{nm}$ spectral bandpass and at $10 \mathrm{~mA}$ in combination with a deuterium lamp. A Zn high-intensity boosted-discharge hollowcathode lamp from Hamamatsu was also used as the spectral radiation source. This lamp was operated with two different discharges (10 mA and $300 \mathrm{~mA})$ in order to increase the emission intensity. During the analytical measurements, the $\mathrm{Zn}$ lamp was operated at low and high currents with a frequency of $100 \mathrm{~Hz}$. At high currents $(300 \mathrm{~mA})$, the absorbance (Abs) measured for a narrow atomic line is low, and the specific absorption of the target element is zero as well, whereas the apparent absorbance caused by a broadband background contributor remains as high as when the lamp is operated at low current levels. In contrast, at conventional current levels $(10 \mathrm{~mA})$ and specific wavelength $(213.856 \mathrm{~nm})$, the energy related to the absorption of the target element is maximum. As a consequence, the difference in absorbance with the lamp operated at low and high currents gives the background correction.

2.3. Test Solutions of $\mathrm{Zn}$ and Fe. Test solutions containing $\mathrm{Zn}$ and $\mathrm{Fe}$ were prepared from the stock solutions described above. Samples were analyzed in pairs to allow for machine drift, for example: $\mathrm{Zn} 1 \mathrm{mg} \mathrm{L}^{-1}$; Zn $1 \mathrm{mgL}^{-1}+\mathrm{Fe} 0 \mathrm{mg} \mathrm{L}^{-1}$; $\mathrm{Zn} 1 \mathrm{mgL}^{-1} ; \mathrm{Zn} 1 \mathrm{mgL}^{-1}+\mathrm{Fe} 0.5 \mathrm{mgL}^{-1}$, Zn $1 \mathrm{mgL}^{-1} ; \mathrm{Zn}$ $1 \mathrm{mg} \mathrm{L}^{-1}+\mathrm{Fe} 1 \mathrm{mg} \mathrm{L}^{-1}$, and so forth. The experiments were conducted with all extracting solutions used (water, acetic acid, and hydroxylamine hydrochloride).

2.4. Soil Sampling and Pretreatment Procedure. The soil samples (agricultural fields and kitchen gardens) used in this work were collected in a contaminated area highly affected by the past atmospheric emissions of two lead and $\mathrm{Zn}$ smelters located in the north of France [28-32]. For each soil type, 
TABLE 1: Sequential extraction procedure (from Rauret et al. [33]).

\begin{tabular}{lll}
\hline Steps & Extracting solutions & Nominal target phases \\
\hline 1 & Acetic acid 0.11 M & $\begin{array}{l}\text { Fraction F1: } \\
\text { exchangeable, water- } \\
\text { and acid-soluble }\end{array}$ \\
2 & $\begin{array}{l}\text { Hydroxylamine }+ \text { hydrochloric } \\
\text { acid } 0.50 \mathrm{M} \text { at } \mathrm{pH} 2\end{array}$ & Fraction F2: reducible \\
3 & $\begin{array}{l}\text { Hydrogen peroxide } 8.8 \mathrm{M},+ \\
\text { ammonium acetate } 1.0 \mathrm{M} \text { at } \mathrm{pH} \mathrm{2} 2\end{array}$ & Fraction F3: oxidizable \\
\hline
\end{tabular}

a composite sample was constituted in the ploughed layer $(0-25 \mathrm{~cm})$ and was prepared following the NF ISO 11464 procedure. The soil samples were air-dried at a temperature below $40^{\circ} \mathrm{C}$, crushed to pass through a $2 \mathrm{~mm}$ stainless steel, and sieved to less than $250 \mu \mathrm{m}$ particle size with an ultracentrifugal mill (Retsch type ZM 200, Hann, Germany). Two certified reference materials, sediment (BCR-701, Piedmont, Italy) and sewage sludge-amended soil (CRM-483, Great Billings Sewage Farm, Northampton), were used for the validation method.

2.5. Extraction Procedures. Digestion of kitchen garden soil samples (KG1 to KG9) was carried out using a microwave oven (Berghof Speedwave MWS-2, Eningen, Germany) with a system to control the temperature inside the reactor pressure vessel. Initially, $300 \mathrm{mg}$ of each sample was transferred to a $100 \mathrm{~mL}$ digestion tube, and a mixture of nitric acid $(70 \%$, $(\mathrm{m} / \mathrm{m}), 1.5 \mathrm{~mL})$ and hydrochloric acid $(37 \%,(\mathrm{~m} / \mathrm{m}), 4.5 \mathrm{~mL})$ was added. After mineralization, digestion products were completed to $25 \mathrm{~mL}$ with doubly distilled water and stored in acid-washed plastic bottles at $4^{\circ} \mathrm{C}$ prior to analysis.

Water-soluble metal ions were extracted from kitchen garden soils in triplicate with the following procedure: $3 \mathrm{~g}$ of each representative sample was shaken with a soil/extractant ratio of $1 / 10(\mathrm{w} / \mathrm{v})$ using a rotor disc $(10 \mathrm{rpm})$ for $2 \mathrm{~h}$. The extract was separated from the solid residue by centrifugation (4,530 rpm, Rotanta 460 Hettich, Tuttlingen, Germany) for $20 \mathrm{~min}$ at room temperature. Afterwards, the solution was filtered over an acetate Millipore membrane (Millipore, $0.45 \mu \mathrm{m}$ porosity, Minisart). The solution was then placed in a polypropylene container and stored at $4^{\circ} \mathrm{C}$ until metal analysis.

The three-step extraction procedure was used to determine $\mathrm{Zn}$ fractionation in the certified and contaminated agricultural soils (A1 to A10) [33]. Each of these steps was noted as being fraction F1, F2, or F3 (Table 1).

Zinc and $\mathrm{Fe}$ concentrations were expressed as $\mathrm{mg} \mathrm{kg}^{-1}$ dry weight (DW). For this, the moisture content of each sample was established by drying a separate 1 -g sample in an oven (Binder, Tuttlingen, Germany) at $105 \pm 2{ }^{\circ} \mathrm{C}$ until it reached a constant mass according to the NF ISO 11465 standard.

2.6. Statistical Analyses. The Mann-Whitney $U$ test (nonparametric statistical test) was used to find out the influence of $\mathrm{Fe}$ in the determination of $\mathrm{Zn}$ concentrations in the test solutions. For each extracting solution and background

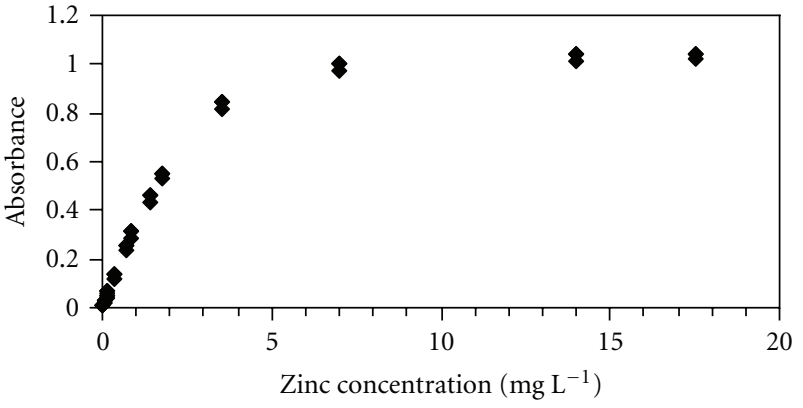

Figure 1: Analytical curve for $\mathrm{Zn}$ in $0.11 \mathrm{M}$ acetic acid measured in FAAS with the HSSR method at $213.856 \mathrm{~nm}$.

corrector, this test was carried out to determine significant differences among $\mathrm{Zn}$ concentrations according to the background corrector and certified or indicative values. All statistical tests were performed using Statistica 6.0 (Statsoft, Tulsa, OK, USA) for Windows. The level of significance was set at $P<0.05$.

\section{Results and Discussion}

3.1. Analytical Performance and Spectroscopic Conditions. Analyses were carried out using each batch of solutions as reagent blanks. The figures of merit of both methods were established using each extracting solution [34] and are shown in Table 2.

The calibrations covered $\mathrm{Zn}$ concentrations ranging from 2 to $25 \mu \mathrm{g} \mathrm{L}-1$ and were linear. The correlation coefficient ranged from 0.9983 to 0.9993 , depending on the extracting solutions. In all experiments, the slopes of the calibration curves as well as the dynamic calibration ranges obtained with the HSSR method were slightly lower than those from the $\mathrm{D}_{2}$ method. These results indicate that the HSSR method had the lowest sensitivity and imply that the limiting absorbance values are smaller than those for the $\mathrm{D}_{2}$ method. As recorded for other elements [35], the cause of the calibration curve flattening is probably due to the high stray-light levels of the boosted-discharge hollow-cathode lamp. In contrast to the results obtained with the $\mathrm{D}_{2}$ method, no roll-over (i.e., a decrease of absorbance at high concentrations) occurred for $\mathrm{Zn}$ in the extracting solutions with the HSSR method (Figure 1).

Limits of detection (LOD) were defined as the concentration equivalent to three times the reagent blank (water, acetic acid, hydroxylamine hydrochloride, ammonium acetate at $\mathrm{pH}=2$, nitric acid $14 \% ; n=10)$. Using the HSSR method, the LOD values were the lowest (Table 2). For instance, LOD values in F1 and F3 fractions were 3.5-fold and 3.7-fold lower than those obtained with the $\mathrm{D}_{2}$ method. Improvement of the LOD may be due to the reduction of the baseline noise and the better stability during the flame atomization of $\mathrm{Zn}$ when the HSSR method was used. The precision of this method was evaluated as the relative standard deviation (R.S.D) of 13 replicate determinations of $\mathrm{Zn}$ at 5 and $10 \mu \mathrm{g} \mathrm{L}-1$ and 0.5 and $1 \mathrm{mg} \mathrm{L}^{-1}$ in each extracting solution. The R.S.D ranged from 0.12 to $1.37 \%$, reflecting a good 
TABLE 2: Calibration data for the determination of $\mathrm{Zn}$.

\begin{tabular}{|c|c|c|c|}
\hline Background corrector & Calibration range $\left(\mu \mathrm{g} \mathrm{L}^{-1}\right)$ & Equation of calibration curves & $\operatorname{LOD}\left(\mu \mathrm{g} \mathrm{L}^{-1}\right)$ \\
\hline $\mathrm{D}_{2}$-FAAS & $2-25$ & $\begin{array}{c}\text { Abs }=0.47790[\mathrm{Zn}]+0.00553 \\
R^{2}=0.9991\end{array}$ & 2.8 \\
\hline HSSR-FAAS & $2-25$ & $\begin{array}{c}\text { Abs }=0.44075[\mathrm{Zn}]+0.00015 \\
R^{2}=0.9988\end{array}$ & 1.5 \\
\hline $\mathrm{D}_{2}-\mathrm{FAAS}^{\mathrm{b}}$ & $2-25$ & $\begin{array}{c}\mathrm{Abs}=0.37643[\mathrm{Zn}]+0.00030 \\
R^{2}=0.9993\end{array}$ & 6.5 \\
\hline HSSR-FAAS ${ }^{\mathrm{b}}$ & $2-25$ & $\begin{array}{c}\mathrm{Abs}=0.37154[\mathrm{Zn}]+0.00074 \\
R^{2}=0.9992\end{array}$ & 1.9 \\
\hline $\mathrm{D}_{2}-\mathrm{FAAS}^{\mathrm{c}}$ & $2-25$ & $\begin{array}{c}\mathrm{Abs}=0.42581[\mathrm{Zn}]+0.00080 \\
R^{2}=0.9992\end{array}$ & 3.8 \\
\hline HSSR-FAASc & $2-25$ & $\begin{array}{c}\text { Abs }=0.31517[\mathrm{Zn}]-0.00044 \\
R^{2}=0.9991\end{array}$ & 1.6 \\
\hline $\mathrm{D}_{2}$-FAAS ${ }^{\mathrm{d}}$ & $2-25$ & $\begin{array}{c}\text { Abs }=0.42600[\mathrm{Zn}]+0.00038 \\
R^{2}=0.9973\end{array}$ & 2.6 \\
\hline HSSR-FAAS $^{\mathrm{d}}$ & $2-25$ & $\begin{array}{c}\text { Abs }=0.27455[\mathrm{Zn}]-0.00029 \\
R^{2}=0.9981\end{array}$ & 0.7 \\
\hline $\mathrm{D}_{2}-\mathrm{FAAS}^{\mathrm{e}}$ & $2-25$ & $\begin{array}{c}\mathrm{Abs}=0.36182[\mathrm{Zn}]+0.00015 \\
R^{2}=0.9987\end{array}$ & 3.1 \\
\hline HSSR-FAAS ${ }^{e}$ & $2-25$ & $\begin{array}{c}\text { Abs }=0.32234[\mathrm{Zn}]-0.00070 \\
R^{2}=0.9993\end{array}$ & 1.9 \\
\hline
\end{tabular}

\footnotetext{
${ }^{\mathrm{a}}$ In water.

${ }^{\mathrm{b}}$ In $0.11 \mathrm{M}$ acetic acid.

${ }^{\mathrm{c}}$ In $0.5 \mathrm{M}$ hydroxylamine hydrochloride (F2).

${ }^{\mathrm{d}}$ In $1 \mathrm{M}$ ammonium acetate $\mathrm{pH}=2$ (F3).

e In $\mathrm{HNO}_{3}$ 14\%.
}

reproducibility of the background corrector effects with solutions at low level of $\mathrm{Zn}$ (in the same order of magnitude of the LOD). On the other hand, under the working conditions (dilute nitric acid) no interference related to the overlapping analytical line of $\mathrm{Zn}$ at $213.856 \mathrm{~nm}$ with $\mathrm{NO}$ molecular absorption bands in the air-acetylene flame was detected. This result is in accordance with phenomena reported by de Oliveira et al. [36].

3.2. Determination of $\mathrm{Zn}$ in Test Solutions. The effects of Fe on $\mathrm{Zn}$ concentrations in water were studied with the two configurations selected for background correction (Figure 2). An overestimation of $\mathrm{Zn}$ concentrations measured in spiked solutions with the $\mathrm{D}_{2}$ method was observed for $\mathrm{Zn}$ at $0.01 \mathrm{mg} \mathrm{L}^{-1}, \mathrm{Zn}$ at $0.5 \mathrm{mg} \mathrm{L}^{-1}$ and $\mathrm{Fe}>250 \mathrm{mg} \mathrm{L}^{-1}$, and $\mathrm{Zn}$ at $1 \mathrm{mg} \mathrm{L}^{-1}$ and $\mathrm{Fe}>500 \mathrm{mg} \mathrm{L}^{-1}$. Surprisingly, $\mathrm{Zn}$ concentrations in these solutions with $\mathrm{Fe}$ concentrations ranging from 0.5 to $100 \mathrm{mg} \mathrm{L}^{-1}$ were lower than $1 \mathrm{mg} \mathrm{L}^{-1}$, reflecting an overcompensation of the deuterium background correction. In contrast, Fe concentrations below $25 \mathrm{mg} \mathrm{L}^{-1}$ did not cause any interference for deuterium corrector in the solution of $\mathrm{Zn}$ at $0.5 \mathrm{mg} \mathrm{L}^{-1}$ (Figures 2 and 3). These results show that the under- and overcompensation of $\mathrm{Zn}$ concentrations using the deuterium corrector depended on $\mathrm{Zn}$ concentrations and $\mathrm{Fe} / \mathrm{Zn}$ ratios.

While serious interferences can be observed with the $\mathrm{D}_{2}$ method due to the low background correction (Figure 3(a)), the presence of Fe did not show a significant effect on $\mathrm{Zn}$ absorbance using the HSSR method (Figure 3(b)). As shown in Figures 2 and 3, experimental $\mathrm{Zn}$ concentration values were very close to the theoretical ones whatever the Fe concentration within the solutions. For instance, in the mixture of $\mathrm{Zn}$ and $\mathrm{Fe}$ at $0.01 \mathrm{mg} \mathrm{L}^{-1}$ and $3,000 \mathrm{mg} \mathrm{L}^{-1}$, respectively, the mean concentration of $\mathrm{Zn}$ measured using the HSSR method was $0.011 \pm 0.001 \mathrm{mg} \mathrm{L}^{-1}$, reflecting the efficiency of this method to eliminate the Fe spectral interference in the course of $\mathrm{Zn}$ determination. Similar results were obtained in $0.11 \mathrm{M}$ acetic acid-spiked solutions (Figure 4). However, the increase in the signal absorbance of $\mathrm{Zn}$ at low concentrations in the acid solutions was lower than that in the water, showing an effect of the solvent on the concentration measured with the $\mathrm{D}_{2}$ method. In contrast, even at low Fe concentrations, this background correction appeared to be unsuitable for the determination of $\mathrm{Zn}$ in $0.5 \mathrm{M}$ hydroxylamine hydrochloride solution, which is included in the SM\&T program (Figure 5). Signal absorbance generally increases with the Fe concentration, leading to higher measured concentrations of $\mathrm{Zn}$ than those present in the solutions. Additionally, the $\mathrm{Zn}$ signal decreased to such an extent that it turned out to be lower than that related to the $\mathrm{Zn}$ concentration at $0.5 \mathrm{mg} \mathrm{L}^{-1}$ indicating either an overcorrection due to the presence of Fe and/or a suppressive effect of chloride ions on the signal of $\mathrm{Zn}$ [37].

For each $\mathrm{Zn}$ concentration, interference effects of Fe were minimized and even avoided when a boosted hollow-cathode lamp was employed for the HSSR background correction. Moreover, the Mann-Whitney $U$ test results showed that Fe interferences were not significant when the Fe concentration was less than $3,000 \mathrm{mg} \mathrm{L}^{-1}$ and the ratio of Fe/Zn was smaller than 300,000 . 

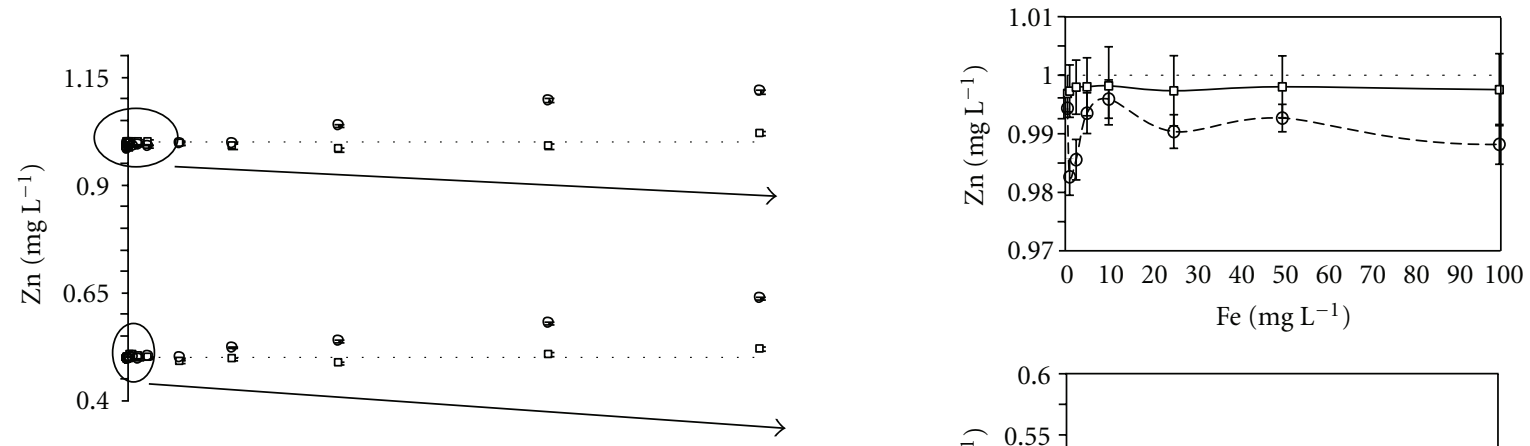

- $D_{2}$-FAAS

$\mathrm{Fe}\left(\mathrm{mg} \mathrm{L}^{-1}\right)$

- HSSR-FAAS
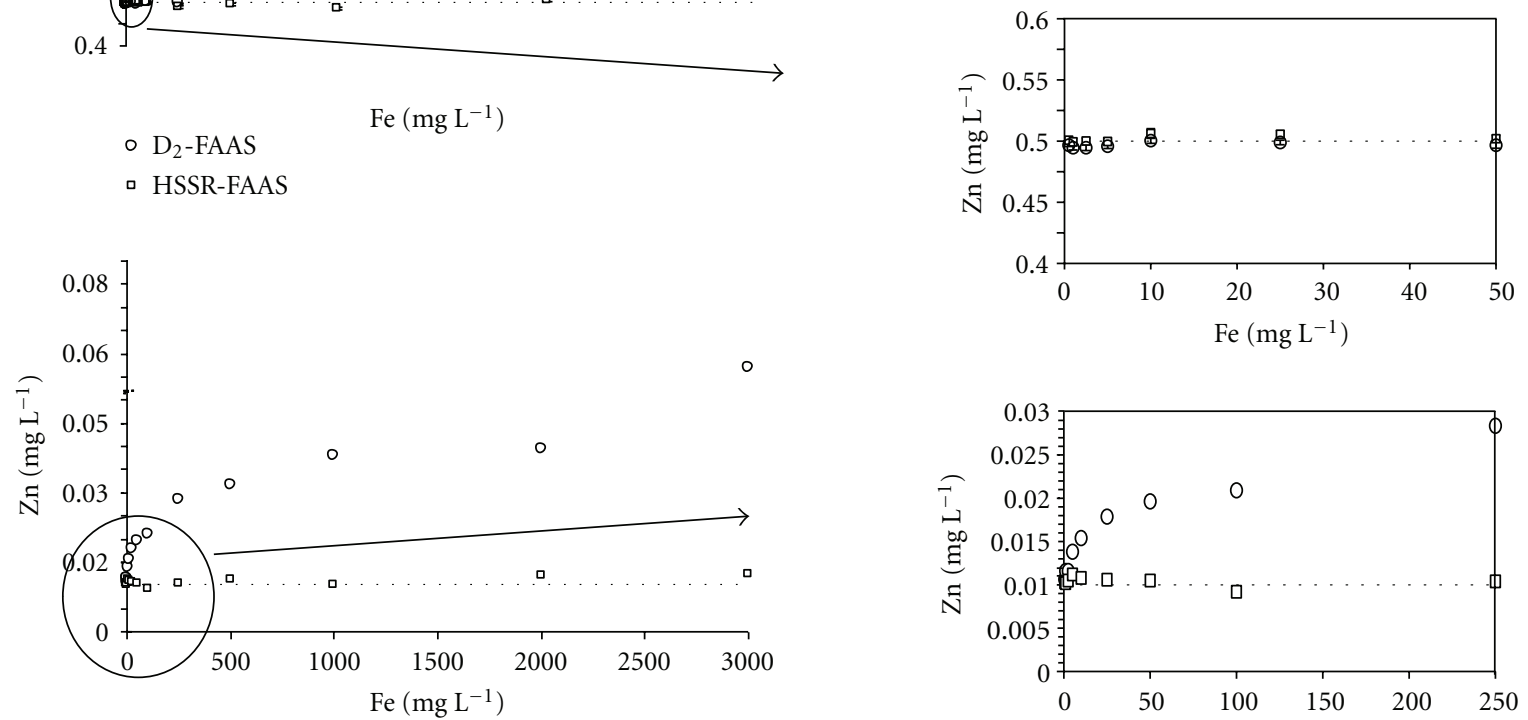

- $\mathrm{D}_{2}$-FAAS

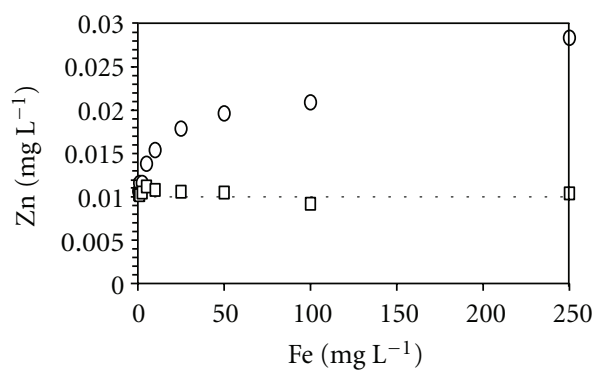

- HSSR-FAAS

Figure 2: Effect of Fe on the three concentrations of $\mathrm{Zn}\left(0.01,0.5\right.$, and $\left.1 \mathrm{mg} \mathrm{L}^{-1}\right)$ measured in water by FAAS at $213.856 \mathrm{~nm}$ with the $\mathrm{D}_{2}$ and HSSR methods.

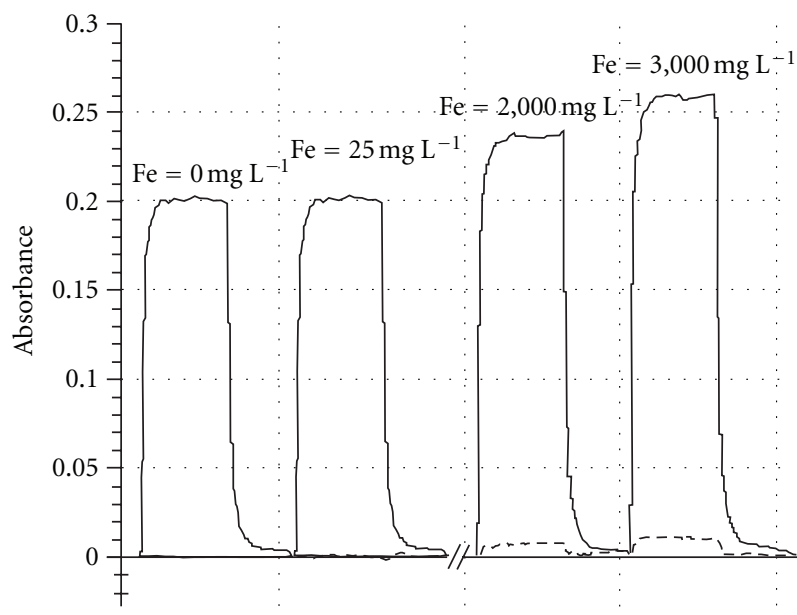

- Zn signal

- - Background

(a)

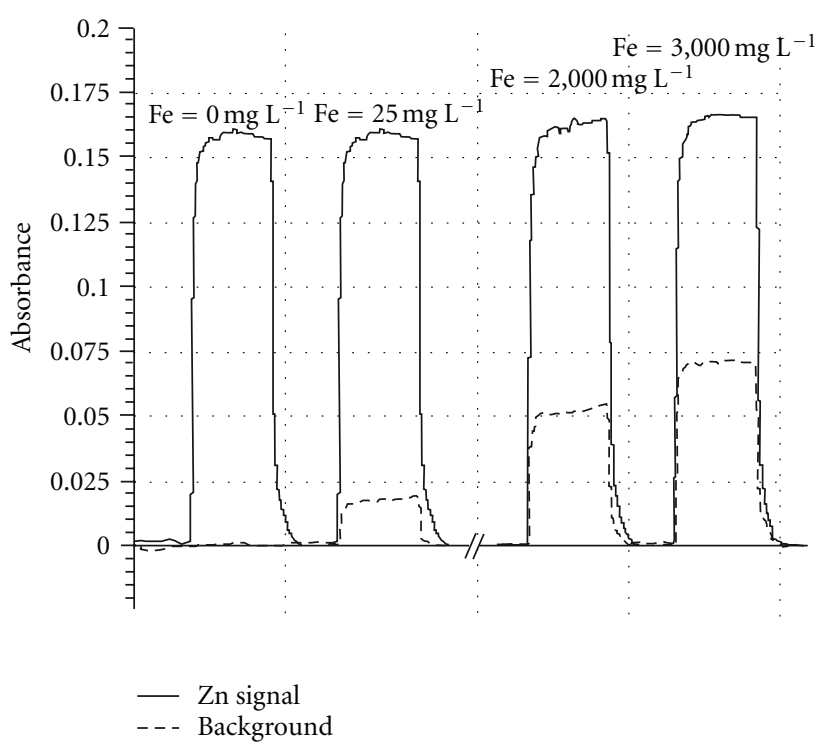

(b)

Figure 3: Effect of Fe in water on the signal of $\mathrm{Zn}$ at $0.5 \mathrm{mg} \mathrm{L}^{-1}$ using (a) deuterium background correction ( $\mathrm{D}_{2}$ method) (b) high-speed self-reversal background correction (HSSR method). 

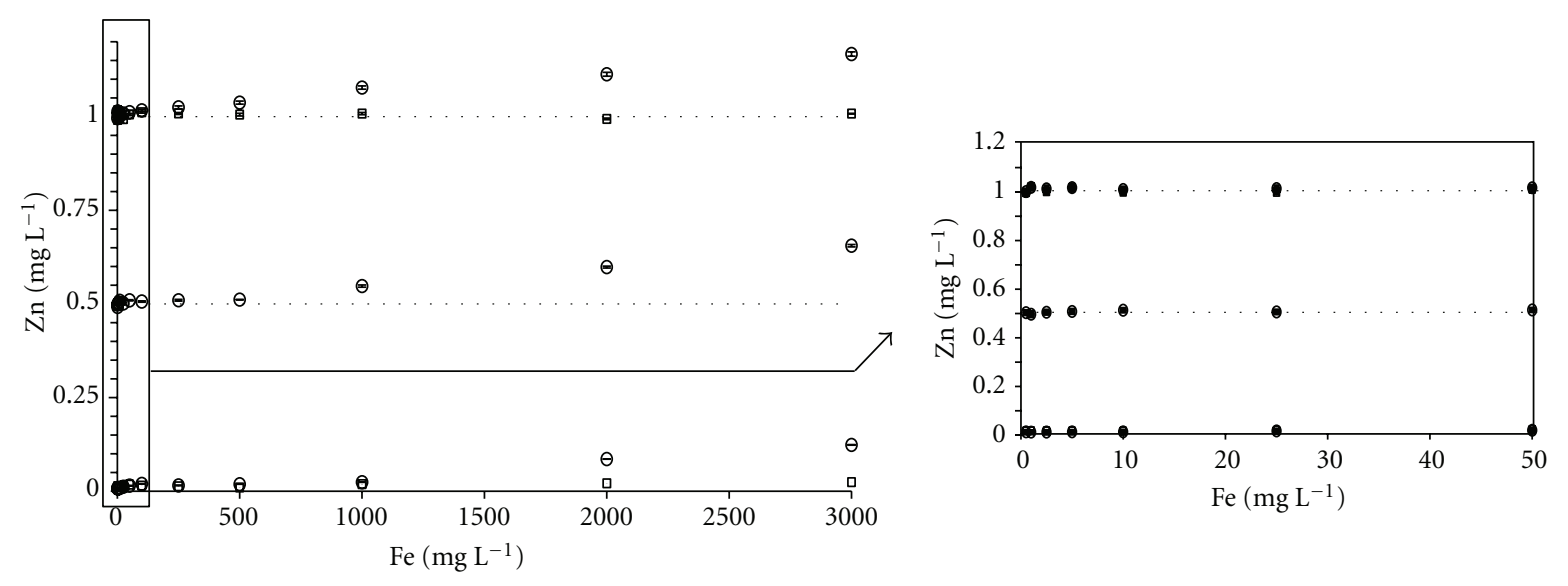

O $\mathrm{D}_{2}$-FAAS

$\square$ HSSR-FAAS

FIGURE 4: Influence of Fe on the three concentrations of $\mathrm{Zn}\left(0.01,0.5\right.$, and $\left.1 \mathrm{mg} \mathrm{L}^{-1}\right)$ measured in $0.11 \mathrm{M}$ acetic acid by FAAS at $213.856 \mathrm{~nm}$ with the $\mathrm{D}_{2}$ and HSSR methods.
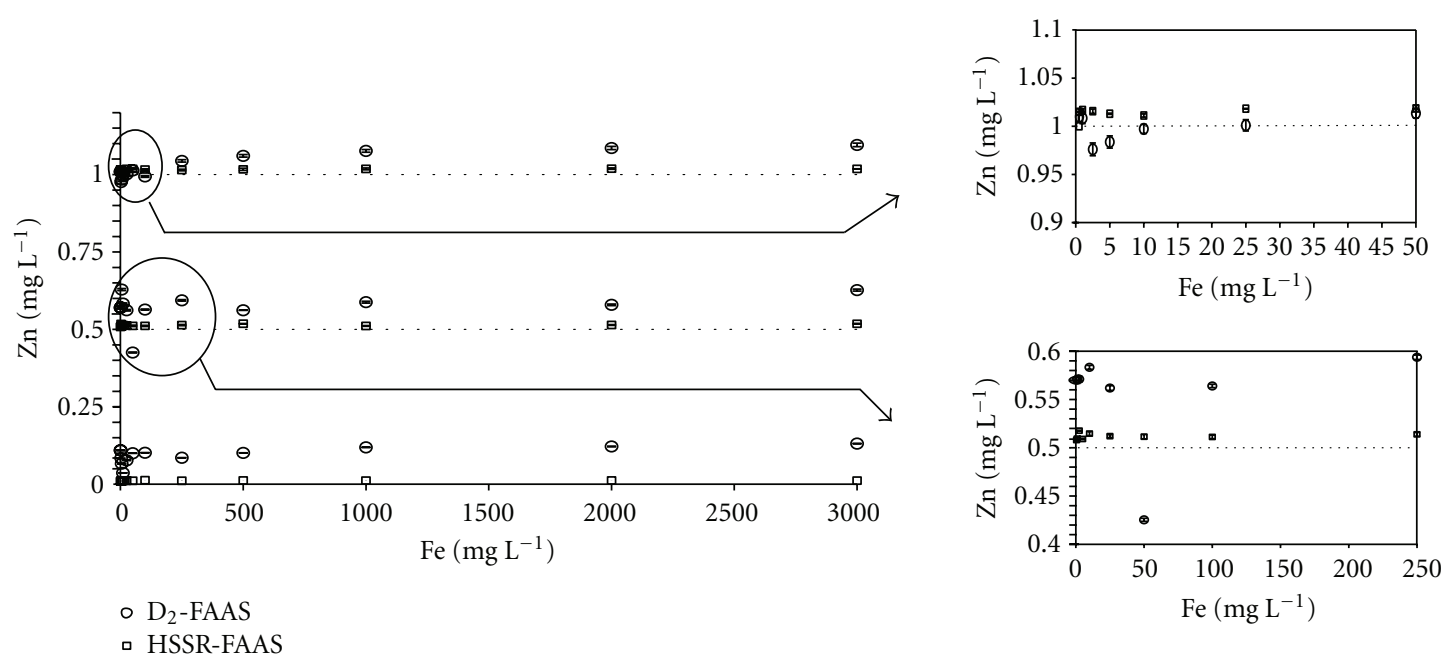

FIGURE 5: Influence of Fe on the three concentrations of $\mathrm{Zn}\left(0.01,0.5\right.$, and $\left.1 \mathrm{mg} \mathrm{L}^{-1}\right)$ measured in $0.5 \mathrm{M}$ hydroxylamine hydrochloride by FAAS at $213.856 \mathrm{~nm}$ with the $\mathrm{D}_{2}$ and HSSR methods.

3.3. Application to Soil Samples. Depending on the physicochemical parameters of soils $(\mathrm{pH}$, organic matter, and Fe contents), the possible migration of $\mathrm{Zn}$ to the depth of contaminated soils located in the studied area was considered [32]. Modeling to predict the solubility of $\mathrm{Zn}$ in soils is therefore very important for the management of polluted soils and industrial sites. In this way, the potential mobility and bioavailability of $\mathrm{Zn}$ are often evaluated using various extracting solutions including water and those used in the SM\&T sequential extraction procedure. There are recurrent problems during the determination of this element by FAAS because of the large amounts of Fe in extracting solutions and the closeness $(0.003 \mathrm{~nm})$ between the two atomic absorption lines of $\mathrm{Zn}$ and $\mathrm{Fe}$ [26]. First of all, pseudototal $\mathrm{Fe}, \mathrm{Cu}$, and $\mathrm{Zn}$ concentrations in kitchen garden soil samples were determined after their microwave-assisted digestion (Table 3 ).
Measurements were performed by dilution of $1: 10$ aqua regia extracts with doubly distilled water except for KG8, for which a dilution of 1:20 was necessary. Zinc concentrations were in the range $0.56-2.90 \mathrm{mg} \mathrm{L}^{-1}$ and $\mathrm{Fe}$ concentrations ranged from 15.8 to $37.7 \mathrm{mg} \mathrm{L}^{-1}$. In almost all cases, $\mathrm{Zn}$ concentrations measured with the $\mathrm{D}_{2}$ method were lower than those determined using the HSSR method, and significant differences $(P<0.05)$ were obtained for KG2, KG3, KG4, KG7, KG8, and KG9. The mean concentration of $\mathrm{Zn}$ found in the BCR-483 material using the $\mathrm{D}_{2}$ method was significantly lower than that measured by Pueyo et al. [40]. This result was attributed to an underestimation of the $\mathrm{Zn}$ concentrations related to overcompensation of the deuterium background correction observed in the $\mathrm{Zn}$ solution at $1 \mathrm{mg} \mathrm{L}^{-1}$ spiked with Fe (Figure 2). In contrast, the values reported for both certified materials obtained with 
TAble 3: Pseudototal Fe, $\mathrm{Cu}$, and $\mathrm{Zn}$ concentrations (mean value \pm standard deviation) measured in certified reference soil $(n=3)$ and kitchen garden (KG) soil samples $(n=3)$.

\begin{tabular}{|c|c|c|c|c|c|}
\hline Samples & $\begin{array}{c}\text { Fe in this work } \\
\left(\mathrm{mg} \mathrm{kg}^{-1}\right)\end{array}$ & $\begin{array}{l}\text { Cu in this work } \\
\left(\mathrm{mg} \mathrm{kg}^{-1}\right)\end{array}$ & $\begin{array}{l}\text { Zn certified value } \\
\left(\mathrm{mg} \mathrm{kg}^{-1}\right)\end{array}$ & $\begin{array}{l}\text { Zn with the } \mathrm{D}_{2} \text { method } \\
\left(\mathrm{mg} \mathrm{kg}^{-1}\right)\end{array}$ & $\begin{array}{l}\text { Zn with the HSSR method } \\
\qquad\left(\mathrm{mg} \mathrm{kg}^{-1}\right)\end{array}$ \\
\hline BCR-483 & $26,642 \pm 1,180^{\mathrm{a}}$ & $403 \pm 11^{\mathrm{c}}$ & $987 \pm 37^{b, c}$ & $939 \pm 48$ & $1,013 \pm 59$ \\
\hline BCR-701 & $36,975 \pm 342^{\mathrm{d}}$ & $43.8 \pm 1.5^{\mathrm{e}}$ & $454 \pm 19^{f}$ & $474 \pm 15$ & $478 \pm 7$ \\
\hline KG1 & $22,496 \pm 717$ & $35.5 \pm 2.3$ & & $821 \pm 10$ & $808 \pm 6$ \\
\hline KG2 & $24,681 \pm 799$ & $25.6 \pm 1.9$ & & $513 \pm 4$ & $531 \pm 7$ \\
\hline KG3 & $23,628 \pm 685$ & $13.3 \pm 1.3$ & & $813 \pm 15$ & $958 \pm 17$ \\
\hline KG4 & $18,846 \pm 578$ & $78.2 \pm 3.1$ & & $867 \pm 9$ & $895 \pm 1$ \\
\hline KG5 & $20,026 \pm 624$ & $74.4 \pm 2.8$ & & $1,052 \pm 21$ & $1,051 \pm 12$ \\
\hline KG6 & $24,399 \pm 790$ & $63.3 \pm 2.3$ & & $1,398 \pm 21$ & $1,410 \pm 24$ \\
\hline KG7 & $18,851 \pm 580$ & $27.3 \pm 1.1$ & & $505 \pm 3$ & $522 \pm 6$ \\
\hline KG8 & $27,029 \pm 890$ & $170.4 \pm 5.4$ & & $4,502 \pm 25$ & $4,842 \pm 54$ \\
\hline KG9 & $31,440 \pm 661$ & $12.6 \pm 1.0$ & & $655 \pm 5$ & $667 \pm 5$ \\
\hline
\end{tabular}

${ }^{\mathrm{a}}$ From Kubová et al. [38], [Fe] $=26,700 \pm 480 \mathrm{mg} \mathrm{kg}^{-1}$.

${ }^{\mathrm{b}}$ Indicative value from Rauret et al. [39], $(n=5)$.

${ }^{\mathrm{c}}$ From Pueyo et al. [40], [Zn] =1,026 $\pm 37 \mathrm{mg} \mathrm{kg}^{-1}$; [Cu] $=373 \pm 14 \mathrm{mg} \mathrm{kg}^{-1}(n=6)$.

${ }^{\mathrm{d}}$ From Kubová et al. (2004) [38], [Fe] $=38,580 \pm 220 \mathrm{mg} \mathrm{kg}^{-1}$.

${ }^{\mathrm{e} C e r t i f i e d ~ v a l u e: ~}[\mathrm{Cu}]=46.4 \pm 1.8 \mathrm{mg} \mathrm{kg}^{-1}(n=6)$.

${ }^{\mathrm{f}}$ From Pueyo et al. [40], [Zn] $=474 \pm 10 \mathrm{mg} \mathrm{kg}^{-1}(n=6)$.

the HSSR method were very close to those found by Pueyo et al. [40] using ICP-MS with all precautions to prevent matrix interferences. As shown for the spiked $\mathrm{Zn}$ solutions, and compared to the certified or indicative values, the accuracy of the results can be explained by the efficiency of the HSSR method in correcting the background of Fe near the analytical line of $\mathrm{Zn}$. In order to supplement this approach, the concentrations of $\mathrm{Zn}$ were measured using the two background correction systems in undiluted water extracts. Data are reported in Table 4. Depending on the Fe/Zn ratio (ranging from 7 to 2,481), the concentrations of $\mathrm{Zn}$ measured with the $\mathrm{D}_{2}$ method were up to 40 -fold higher than those obtained with the HSSR method. The magnitude of the difference between $\mathrm{Zn}$ concentrations in the water extracts from the KG2 soil sample with both background correction systems is in agreement with the results obtained using the spiked $\mathrm{Zn}$ solution at $10 \mu \mathrm{g} \mathrm{L}-1$ with a high $\mathrm{Fe} / \mathrm{Zn}$ ratio. It reflects an undercorrection of the deuterium background system, providing an overestimation of $\mathrm{Zn}$ concentrations. In contrast, the $\mathrm{Zn}$ concentrations found in the water extracting solution from KG8 were not significantly different for the two background systems. From a statistical point of view, the high standard deviation value can explain this result but it seems clear that the low value for the Fe/Zn ratio $(\mathrm{Fe} / \mathrm{Zn}=7.16)$ is a more appropriate explanation.

Analytical studies were further carried out with the extracting solutions included in the 3 steps sequential extraction procedure proposed by the standards measurements and testing program (SM\&T) of the European Union. The mean concentrations of $\mathrm{Zn}$ found with the $\mathrm{D}_{2}$ and HSSR methods in the BCR-701 and BCR-483 certified materials, as well as the certified or indicative values for this analyte and $\mathrm{Fe}$, are shown in Table 5. For both certified materials, significant differences $(P<0.05)$ were found between $\mathrm{Zn}$ concentrations
TABLE 4: Water-extractable Fe and Zn concentrations (mean value \pm standard deviation, $n=3$ ) in kitchen garden (KG) soil samples.

\begin{tabular}{lcccc}
\hline Samples & $\begin{array}{c}\mathrm{Fe} \\
\left(\mathrm{mg} \mathrm{kg}^{-1}\right)\end{array}$ & $\begin{array}{c}\text { Zn with the } \mathrm{D}_{2} \\
\text { method } \\
\left(\mu \mathrm{kg}^{-1}\right)\end{array}$ & $\begin{array}{c}\text { Zn with the } \\
\text { HSSR method } \\
\left(\mu \mathrm{kg}^{-1}\right)\end{array}$ & $\mathrm{Fe} / \mathrm{Zn}$ \\
\hline KG1 & $77.4 \pm 21.2$ & $3,100 \pm 400$ & $2,450 \pm 320$ & 31.6 \\
KG2 & $6.7 \pm 1.4$ & $113 \pm 40$ & $2.7 \pm 0.2$ & 2,481 \\
KG3 & $5.9 \pm 1.2$ & $1,162 \pm 35$ & $844 \pm 21$ & 7.0 \\
KG4 & $68.7 \pm 8.7$ & $3,974 \pm 384$ & $3,230 \pm 298$ & 21.9 \\
KG5 & $5.0 \pm 0.9$ & $799 \pm 90$ & $552 \pm 101$ & 9 \\
KG6 & $113.1 \pm 8.3$ & $5,798 \pm 160$ & $4,850 \pm 130$ & 23.3 \\
KG7 & $35.9 \pm 10.2$ & $1,054 \pm 245$ & $675 \pm 123$ & 53.2 \\
KG8 & $120.0 \pm 23.5$ & $18,224 \pm 2,210$ & $16,764 \pm 2,215$ & 7.1 \\
KG9 & $104.9 \pm 4.3$ & $4,789 \pm 114$ & $4,206 \pm 133$ & 24.9 \\
\hline
\end{tabular}

measured using the $\mathrm{D}_{2}$ method and certified or indicative values. An exception was noted for the $\mathrm{Zn}$ concentration in the F3 fraction of the BCR- 483 certified material. The greatest differences were observed in step 2 , in which $0.5 \mathrm{M}$ hydroxylamine hydrochloride was used to release the free $\mathrm{Fe}$ oxides [41]

As shown in Table 5, the high concentrations of free $\mathrm{Fe}$ in the F2 fraction led to an overestimation of $\mathrm{Zn}$ concentrations, reflecting an undercompensation of the deuterium background system. In contrast, FAAS measurements combined with the HSSR method yielded values were very close to the certified or indicatives ones, showing the efficiency of the method for correcting the Fe spectral interferences. The same general trends were observed for the distribution of $\mathrm{Zn}$ in contaminated agricultural soil samples (Table 6). Zinc concentrations measured with both 
TABLE 5: Certified and obtained Fe and Zn concentrations in BCR-701 $(n=3)$ and BCR-483 $(n=3)$ using the BCR three-step sequential extraction procedure.

\begin{tabular}{|c|c|c|c|c|c|c|c|}
\hline \multirow{5}{*}{ Fraction } & \multirow{5}{*}{ Metal } & \multicolumn{3}{|c|}{ BCR-701 } & \multicolumn{3}{|c|}{ BCR-483 } \\
\hline & & \multirow{2}{*}{ Certified value } & \multicolumn{2}{|c|}{ Obtained value } & \multirow[t]{2}{*}{ Indicative value ${ }^{a}$} & \multicolumn{2}{|c|}{ Obtained value } \\
\hline & & & $\mathrm{D}_{2}$ method & HSSR method & & $\mathrm{D}_{2}$ method & $\begin{array}{l}\text { HSSR } \\
\text { method }\end{array}$ \\
\hline & & mean $\pm U$ & mean $\pm \mathrm{SD}$ & mean $\pm \mathrm{SD}$ & mean $\pm \mathrm{U}$ & mean $\pm \mathrm{SD}$ & mean $\pm S D$ \\
\hline & & $\left(\mathrm{mg} \mathrm{kg}^{-1}\right)$ & $\left(\mathrm{mg} \mathrm{kg}^{-1}\right)$ & $\left(\mathrm{mg} \mathrm{kg}^{-1}\right)$ & $\left(\mathrm{mg} \mathrm{kg}^{-1}\right)$ & $\left(\mathrm{mg} \mathrm{kg}^{-1}\right)$ & $\left(\mathrm{mg} \mathrm{kg}^{-1}\right)$ \\
\hline \multirow{2}{*}{ F1 } & $\mathrm{Zn}$ & $205 \pm 6$ & $238 \pm 12$ & $205 \pm 13$ & $441 \pm 39$ & $458 \pm 11$ & $442 \pm 12$ \\
\hline & $\mathrm{Fe}$ & $71 \pm 1^{\mathrm{b}}$ & $83 \pm 1$ & & $36 \pm 2^{\mathrm{b}}$ & $36 \pm 2$ & \\
\hline \multirow{2}{*}{ F2 } & $\mathrm{Zn}$ & $114 \pm 5$ & $162 \pm 13$ & $123 \pm 3$ & $438 \pm 56$ & $463 \pm 18$ & $439 \pm 20$ \\
\hline & $\mathrm{Fe}$ & $7,698 \pm 106^{\mathrm{b}}$ & $7,732 \pm 109$ & & $6,691 \pm 198^{b}$ & $6,520 \pm 219$ & \\
\hline \multirow{2}{*}{ F3 } & $\mathrm{Zn}$ & $45.7 \pm 4.0$ & $37.8 \pm 1.2$ & $46.6 \pm 1.2$ & $37.1 \pm 9.9$ & $35.7 \pm 1.2$ & $39.2 \pm 1.5$ \\
\hline & $\mathrm{Fe}$ & $1,097 \pm 53^{\mathrm{b}}$ & $1,195 \pm 45$ & & $1,153 \pm 29^{b}$ & $1,164 \pm 149$ & \\
\hline
\end{tabular}

U: uncertainty (half-width of the $95 \%$ confidence interval); SD: standard deviation.

${ }^{\text {a}}$ From Rauret et al. [39].

${ }^{b}$ Indicative values from Kubová et al. [38].

TABLE 6: Fe and Zn concentrations at each step of the SM\&T sequential extraction procedure.

\begin{tabular}{|c|c|c|c|c|c|c|c|c|c|}
\hline \multirow{4}{*}{ Samples } & \multicolumn{9}{|c|}{ Fractions } \\
\hline & \multicolumn{3}{|c|}{$\mathrm{F} 1$} & \multicolumn{3}{|c|}{$\mathrm{F} 2$} & \multicolumn{3}{|c|}{ F3 } \\
\hline & \multicolumn{2}{|c|}{$\mathrm{Zn}\left(\mathrm{mg} \mathrm{kg}^{-1}\right)$} & \multirow[t]{2}{*}{$\begin{array}{c}\mathrm{Fe} \\
\left(\mathrm{mg} \mathrm{kg}^{-1}\right)\end{array}$} & \multicolumn{2}{|c|}{$\mathrm{Zn}\left(\mathrm{mg} \mathrm{kg}^{-1}\right)$} & \multirow[t]{2}{*}{$\begin{array}{c}\mathrm{Fe} \\
\left(\mathrm{mg} \mathrm{kg}^{-1}\right)\end{array}$} & \multicolumn{2}{|c|}{$\mathrm{Zn}\left(\mathrm{mg} \mathrm{kg}^{-1}\right)$} & \multirow[t]{2}{*}{$\begin{array}{c}\mathrm{Fe} \\
\left(\mathrm{mg} \mathrm{kg}^{-1}\right)\end{array}$} \\
\hline & $\mathrm{D}_{2}$ method & HSSR method & & $\mathrm{D}_{2}$ method & HSSR method & & $\mathrm{D}_{2}$ method & HSSR method & \\
\hline$\overline{\mathrm{A} 1}$ & 46.7 & 50.7 & 3.4 & 60.2 & 54.6 & 1,223 & 27.0 & 20.1 & 494.5 \\
\hline A2 & 132.6 & 120.5 & 18.9 & 143.8 & 138.3 & 1,361 & 114.5 & 111.7 & 1,357 \\
\hline A3 & 181.3 & 211.1 & 23.4 & 135.6 & 128.6 & 1,187 & 123.5 & 102.8 & 1,225 \\
\hline A4 & 117.0 & 124.0 & 18.5 & 138.0 & 130.3 & 1,398 & 136.9 & 119.3 & 1,115 \\
\hline A5 & 619.6 & 565.5 & 67.3 & 288.5 & 265.1 & 1,337 & 1,453 & 1,450 & 4,762 \\
\hline A6 & 108.7 & 111.8 & 0.6 & 205.6 & 177.7 & 1,220 & 77.7 & 65.4 & 638.8 \\
\hline A7 & 87.5 & 78.5 & 1.5 & 85.0 & 70.1 & 873.6 & 53.3 & 49.5 & 498.2 \\
\hline A8 & 35.2 & 33.9 & 0.2 & 288.1 & 277.2 & 1,800 & 95.7 & 85.0 & 1,046 \\
\hline A9 & 72.5 & 71.1 & 0.8 & 155.6 & 146.6 & 2,142 & 59.8 & 47.9 & 930.9 \\
\hline A10 & 147.0 & 152.5 & 18.9 & 397.7 & 409.8 & 2,626 & 347.8 & 334.1 & 3,498 \\
\hline
\end{tabular}

TABle 7: Determination of traces of $\mathrm{Zn}$ in $2 \%$ Fe solution by direct aspiration-FAAS using the $\mathrm{D}_{2}$ and the HSSR methods.

\begin{tabular}{lll}
\hline $\begin{array}{l}\text { Zn concentration } \\
\text { added }\left(\mathrm{mg} \mathrm{L}^{-1}\right)\end{array}$ & \multicolumn{2}{c}{ Zn concentration found $\left(\mathrm{mg} \mathrm{L}^{-1}\right)$} \\
\hline 0.5 & $0.74 \pm 0.07$ & HSSR method \\
0.75 & $1.02 \pm 0.05$ & $0.54 \pm 0.03$ \\
1 & $1.20 \pm 0.05$ & $0.97 \pm 0.02$ \\
1.5 & $1.86 \pm 0.01$ & $1.49 \pm 0.01$ \\
\hline
\end{tabular}

Means and standard deviations for triplicate analyses.

background systems in the first fraction were very close to each other. An exception was observed with the A5 sample, which presented the highest $\mathrm{Fe}$ concentration. In contrast, differences between the concentrations of $\mathrm{Zn}$ in fractions $\mathrm{F} 2$ and F3 were up to $35 \%$, mainly due to the order of magnitude of Fe concentrations in these fractions (from 494 to $3,498 \mathrm{mg} \mathrm{kg}^{-1}$ ). Despite the high Fe concentration found in
F2 of sample A10, it is important to note that the mean concentration of $\mathrm{Zn}$ was lower using the $\mathrm{D}_{2}$ method than the HSSR method. Taking into account the liquid/solid ratio and the dilution factor, the concentrations of $\mathrm{Zn}$ and Fe were 0.99 and $6.6 \mathrm{mg} \mathrm{L}^{-1}$, respectively. The result is consistent with the data presented in Figure 5 reflecting an underestimation of $\mathrm{Zn}$ at $1 \mathrm{mg} \mathrm{L}^{-1}$ in presence of Fe from 2.5 to $10 \mathrm{mg} \mathrm{L}^{-1}$ using the $\mathrm{D}_{2}$ method. All of these results confirm that the HSSR method is an efficient background compensation of the spectral interferences caused by Fe during Zn measurements using FAAS.

3.4. Efficiency of the HSSR Method. As reported by Sweileh and El-Nemma [26], the determination of $\mathrm{Zn}$ in the presence of high concentrations of Fe (e.g., some geological samples, meteorites, or steels) is problematic using FAAS. From our investigations, the $\mathrm{Zn}$-free solution containing $0.2 \%$, $0.3 \%$, and $2 \% \mathrm{Fe}$ appeared to contain $0.13,0.14$, and 
$0.39 \mathrm{mg} \mathrm{L}^{-1}$ of $\mathrm{Zn}$, respectively. The last value is in agreement with the previously reported spectral interference of $\mathrm{Fe}$ in the determination of $\mathrm{Zn}$ [26] indicating that the deuterium background correction is not always suitable for compensating the Fe spectral interference in $\mathrm{Zn}$. We determined the trace amounts of $\mathrm{Zn}$ in the $2 \%$ Fe solution with the proposed method. The results are summarized in Table 7. The reported values of $\mathrm{Zn}$ measured by FAAS with the $\mathrm{D}_{2}$ method were greater than the $\mathrm{Zn}$ concentrations added in the Fe solution. In contrast, the $\mathrm{Zn}$ concentrations measured by FAAS with the HSSR method were very close to the added concentrations, proving the effectiveness of the proposed technique for correcting matrix effects and spectral interferences in FAAS.

\section{Conclusions}

The extractable concentrations of $\mathrm{Zn}$ (aqua regia, water, and sequential extractions) were determined by FAAS with two background correction systems. The first was based on the well-known deuterium background correction and the second involved the use of a single $\mathrm{Zn}$ hollow-cathode lamp pulsed with currents ranging from 10 to $300 \mathrm{~mA}$ with a frequency of $100 \mathrm{~Hz}$. Depending on the extracting solutions, but also on the $\mathrm{Zn}$ concentration and the Fe/Zn ratio, it was demonstrated that background correction with a deuterium lamp led to significant errors (e.g., over- and underestimation). In contrast, the HSSR method appeared to be a more versatile technique for the compensation of spectral interferences caused by absorption line overlapping. The proposed method allowed $\mathrm{Zn}$ determination at the $\mu \mathrm{g} \mathrm{L}^{-1}$ level in the presence of large concentrations of Fe with high stability and sensitivity. With a good LOD and R.S.D, this method shows promise for monitoring zinc concentrations in various Fe-containing samples without any pretreatment.

\section{Standard}

NF ISO 11464. Soil Quality—Pretreatment of samples for physicochemical analyses. AFNOR, 1994, $9 \mathrm{p}$.

NF ISO 11465. Soil Quality-Determination of dry matter and water content on a mass basis-gravimetric method. AFNOR, 1994, 4 p.

\section{References}

[1] J. M. Anzano and P. Gónzalez, "Determination of iron and copper in peanuts by flame atomic absorption spectrometry using acid digestion," Microchemical Journal, vol. 64, no. 2, pp. 141-145, 2000.

[2] S. Soriano, A. D. P. Netto, and R. J. Cassella, "Determination of $\mathrm{Cu}, \mathrm{Fe}, \mathrm{Mn}$ and $\mathrm{Zn}$ by flame atomic absorption spectrometry in multivitamin/multimineral dosage forms or tablets after an acidic extraction," Journal of Pharmaceutical and Biomedical Analysis, vol. 43, no. 1, pp. 304-310, 2007.

[3] M. D. Silvestre, M. J. Lagarda, R. Farré, C. Martínez-Costa, and J. Brines, "Copper, iron and zinc determinations in human milk using FAAS with microwave digestion," Food Chemistry, vol. 68, no. 1, pp. 95-99, 2000.
[4] L. Kékedy-Nagy, Y. Jun, E. Darvasi, and L. Kékedy-Nagy Jr., "Determination of zinc in vegetal tissue microsamples by platinum-wire loop in flame atomization atomic absorption spectrometry," Journal of Biochemical and Biophysical Methods, vol. 70, no. 6, pp. 1234-1239, 2008.

[5] M. A. Taher, "Atomic absorption spectrometric determination of ultra trace amounts of zinc after preconcentration with the ion pair of 2-(5-bromo-2-pyridylazo)-5- diethylaminophenol and ammonium tetraphenylborate on microcrystalline naphthalene or by column method," Talanta, vol. 52, no. 2, pp. 181$188,2000$.

[6] D. L. Giokas, E. K. Paleologos, M. I. Prodromidis, and M. I. Karayannis, "Development of 1-(2-pyridylazo)-2-naphtholmodified polymeric membranes for the effective batch preconcentration and determination of zinc traces with flame atomic absorption spectrometry," Talanta, vol. 56, no. 3, pp. 491-498, 2002.

[7] M. Soylak, S. Saracoglu, U. Divrikli, and L. Elci, "Coprecipitation of heavy metals with erbium hydroxide for their flame atomic absorption spectrometric determinations in environmental samples," Talanta, vol. 66, no. 5, pp. 1098-1102, 2005.

[8] O. D. Uluozlu, M. Tuzen, D. Mendil, and M. Soylak, "Coprecipitation of trace elements with $\mathrm{Ni}^{2+} / 2$-Nitroso-1-naphthol4-sulfonic acid and their determination by flame atomic absorption spectrometry," Journal of Hazardous Materials, vol. 176, no. 1-3, pp. 1032-1037, 2010.

[9] I. Komjarova and R. Blust, "Comparison of liquid-liquid extraction, solid-phase extraction and co-precipitation preconcentration methods for the determination of cadmium, copper, nickel, lead and zinc in seawater," Analytica Chimica Acta, vol. 576, no. 2, pp. 221-228, 2006.

[10] P. S. Roldan, I. L. Alcântara, C. C. F. Padilha, and P. M. Padilha, "Determination of copper, iron, nickel and zinc in gasoline by FAAS after sorption and preconcentration on silica modified with 2-aminotiazole groups," Fuel, vol. 84, no. 2-3, pp. 305309, 2005.

[11] M. Ghaedi, K. Niknam, A. Shokrollahi, E. Niknam, H. Ghaedi, and M. Soylak, "A solid phase extraction procedure for $\mathrm{Fe}^{3+}$, $\mathrm{Cu}^{2+}$ and $\mathrm{Zn}^{2+}$ ions on 2-phenyl-1H-benzo[d] imidazole loaded on Triton X-100-coated polyvinyl chloride," Journal of Hazardous Materials, vol. 158, no. 1, pp. 131-136, 2008.

[12] M. Tuzen and E. Melek, "Solid-phase extraction of copper, iron and zinc ions on Bacillus thuringiensis israelensis loaded on Dowex optipore V-493," Journal of Hazardous Materials, vol. 159, no. 2-3, pp. 335-341, 2008.

[13] M. Ghaedi, K. Niknam, K. Taheri, H. Hossainian, and M. Soylak, "Flame atomic absorption spectrometric determination of copper, zinc and manganese after solid-phase extraction using 2,6-dichlorophenyl-3,3-bis(indolyl)methane loaded on Amberlite XAD-16," Food and Chemical Toxicology, vol. 48, no. 3, pp. 891-897, 2010.

[14] A. S. Saljooghi, S. J. Fatemi, and D. Afzali, "Determination of trace amounts of zinc by flame atomic absorption spectrometry after separation and preconcentration onto modified natural analcime zeolite loaded 2,3,5,6-tetra(2-pyridyl)pyrazine," Bulletin of the Chemical Society of Ethiopia, vol. 24, no. 1, pp. 127-132, 2010.

[15] S. Vellaichamy and K. Palanivelu, "Preconcentration and separation of copper, nickel and zinc in aqueous samples by flame atomic absorption spectrometry after column solidphase extraction onto MWCNTs impregnated with D2EHPATOPO mixture," Journal of Hazardous Materials, vol. 185, no. 2-3, pp. 1131-1139, 2011. 
[16] N. Dallali, M. M. Zahedi, and Y. Yamini, "Simultaneous cloud point extraction and determination of $\mathrm{Zn}, \mathrm{Co}, \mathrm{Ni}$ and $\mathrm{Pb}$ by flame atomic absorption spectrometry, using 2-guanidinobenzimidazole as the complexing agent," Scientia Iranica, vol. 14, no. 4, pp. 291-296, 2007.

[17] H. S. Ferreira, A. C. N. Santos, L. A. Portugal, A. C. S. Costa, M. Miró, and S. L. C. Ferreira, "Pre-concentration procedure for determination of copper and zinc in food samples by sequential multi-element flame atomic absorption spectrometry," Talanta, vol. 77, no. 1, pp. 73-76, 2008.

[18] S. Zhao, X. Xia, G. Yu, and B. Yang, "Simultaneous determination of iron and zinc by $\mathrm{pH}$ gradient construction in a flowinjection system," Talanta, vol. 46, no. 5, pp. 845-850, 1998.

[19] J. Chen and K. C. Teo, "Determination of cadmium, copper, lead and zinc in water samples by flame atomic absorption spectrometry after cloud point extraction," Analytica Chimica Acta, vol. 450, no. 1-2, pp. 215-222, 2001.

[20] W. N. L. dos Santos, C. M. C. Santos, and S. L. C. Ferreira, "Application of three-variables Doehlert matrix for optimisation of an on-line pre-concentration system for zinc determination in natural water samples by flame atomic absorption spectrometry," Microchemical Journal, vol. 75, no. 3, pp. 211221, 2003.

[21] W. R. Kelly and C. B. Moore, "Iron spectral interference in the determination of zinc by atomic absorption spectrometry," Analytical Chemistry, vol. 45, no. 7, pp. 1274-1275, 1973.

[22] B. Welz, H. Becker-Ross, S. Florek, and U. Heitmann, HighResolution Continuum Source AAS: The Better Way to Do Atomic Absorption Spectrometry, Wiley-VCH, Weinheim, Germany, 2005.

[23] B. Welz, H. Becker-Ross, S. Florek, U. Heitmann, and M. G. R. Vale, "High-resolution continuum-source atomic absorption spectrometry-what can we expect?" Journal of the Brazilian Chemical Society, vol. 14, no. 2, pp. 220-229, 2003.

[24] M. Gallego, M. Garcia-Vargas, and M. Valcárcel, "Analytical applications of picolinealdehyde salicyloylhydrazone. III. Extraction and determination of zinc by atomic absorption spectrophotometry," Microchemical Journal, vol. 27, no. 3, pp. 328-338, 1982.

[25] J. A. Sweileh and F. F. Cantwell, "Sample introduction by solvent extraction/flow injection to eliminate interferences ion atomic absorption spectroscopy," Analytical Chemistry, vol. 57, no. 2, pp. 420-424, 1985.

[26] J. A. Sweileh and E. M. El-Nemma, "On-line elimination of spectral interference of iron matrix in the flame atomic absorption determination of zinc by anion-exchange separation," Analytica Chimica Acta, vol. 523, no. 2, pp. 287-292, 2004.

[27] M. B. Mansur, S. D. F. Rocha, F. S. Magalhães, and J. D. S. Benedetto, "Selective extraction of zinc(II) over iron(II) from spent hydrochloric acid pickling effluents by liquid-liquid extraction," Journal of Hazardous Materials, vol. 150, no. 3, pp. 669-678, 2008.

[28] S. B. Smith and G. M. Hieftje, "A new background-correction method for atomic absorption spectrometry," Applied Spectroscopy, vol. 37, no. 5, pp. 419-424, 1983.

[29] U. Oppermann, J. Schram, and D. Felkel, "Improved background compensation in atomic absorption spectrometry using the high speed self reversal method," Spectrochimica Acta $B$, vol. 58, no. 8, pp. 1567-1572, 2003.

[30] T. Sterckeman, F. Douay, N. Proix, H. Fourrier, and E. Perdrix, "Assessment of the contamination of cultivated soils by eighteen trace elements around smelters in the North of
France," Water, Air, and Soil Pollution, vol. 135, no. 1-4, pp. 173-194, 2002.

[31] F. Douay, C. Pruvot, H. Roussel et al., "Contamination of urban soils in an area of Northern France polluted by dust emissions of two smelters," Water, Air, and Soil Pollution, vol. 188, no. 1-4, pp. 247-260, 2008.

[32] C. Pruvot, F. Douay, H. Fourrier, and C. Waterlot, "Heavy metals in soil, crops and grass as a source of human exposure in the former mining areas," Journal of Soils and Sediments, vol. 6, no. 4, pp. 215-220, 2006.

[33] G. Rauret, J. F. López-Sánchez, A. Sahuquillo et al., "Improvement of the BCR three step sequential extraction procedure prior to the certification of new sediment and soil reference materials," Journal of Environmental Monitoring, vol. 1, no. 1, pp. 57-61, 1999.

[34] M. Žemberyová, J. Barteková, M. Závadská, and M. Šišoláková, "Determination of bioavailable fractions of $\mathrm{Zn}$, $\mathrm{Cu}, \mathrm{Ni}, \mathrm{Pb}$ and $\mathrm{Cd}$ in soils and sludges by atomic absorption spectrometry," Talanta, vol. 71, no. 4, pp. 1661-1668, 2007.

[35] P. L. Larkins, "The effect of spectral line broadening on the shape of analytical curves obtained using pulsed hollowcathode lamps for background correction," Spectrochimica Acta B, vol. 43, no. 9-11, pp. 1175-1186, 1988.

[36] S. R. de Oliveira, J. L. Raposo Jr., and J. A. G. Neto, "Fast sequential multi-element determination of $\mathrm{Ca}, \mathrm{Mg}, \mathrm{K}, \mathrm{Cu}, \mathrm{Fe}, \mathrm{Mn}$ and $\mathrm{Zn}$ for foliar diagnosis using high-resolution continuum source flame atomic absorption spectrometry: feasibility of secondary lines, side pixel registration and least-squares background correction," Spectrochimica Acta B, vol. 64, no. 6, pp. 593-596, 2009.

[37] D. Y. Sarica, D. Akim, and T. Özden, "Determination of zinc in aerosol samples by discrete nebulization flame atomic absorption spectrometry," Turkish Journal of Chemistry, vol. 26, no. 2, pp. 263-270, 2002.

[38] J. Kubová, V. Streško, M. Bujdoš, P. Matúš, and J. Medved', "Fractionation of various elements in CRMs and in polluted soils," Analytical and Bioanalytical Chemistry, vol. 379, no. 1, pp. 108-114, 2004.

[39] G. Rauret, J. F. López-Sánchez, A. Sahuquillo et al., "Application of a modified BCR sequential extraction (three-step) procedure for the determination of extractable trace metal contents in a sewage sludge amended soil reference material (CRM 483), complemented by a three-year stability study of acetic acid and EDTA extractable metal content," Journal of Environmental Monitoring, vol. 2, no. 3, pp. 228-233, 2000.

[40] M. Pueyo, J. Mateu, A. Rigol, M. Vidal, J. F. López-Sánchez, and G. Rauret, "Use of the modified BCR three-step sequential extraction procedure for the study of trace element dynamics in contaminated soils," Environmental Pollution, vol. 152, no. 2, pp. 330-341, 2008.

[41] C. Waterlot, M. François, and H. C. Dubourguier, "Speciation and distribution of heavy metals in polluted soils," in Proceedings of the 15th Annual Meeting of SETAC, Lille, France, 1995. 


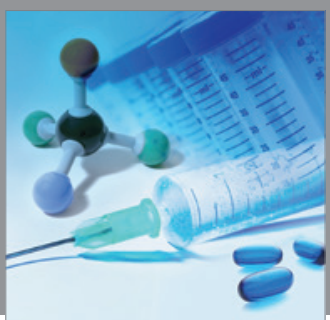

International Journal of

Medicinal Chemistry

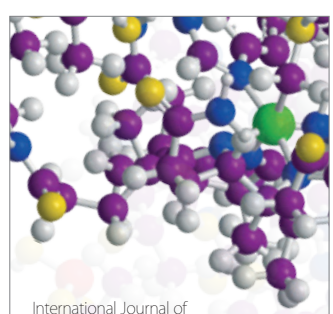

Carbohydrate Chemistry

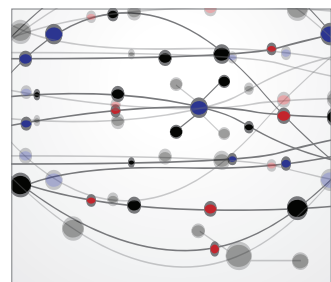

The Scientific World Journal
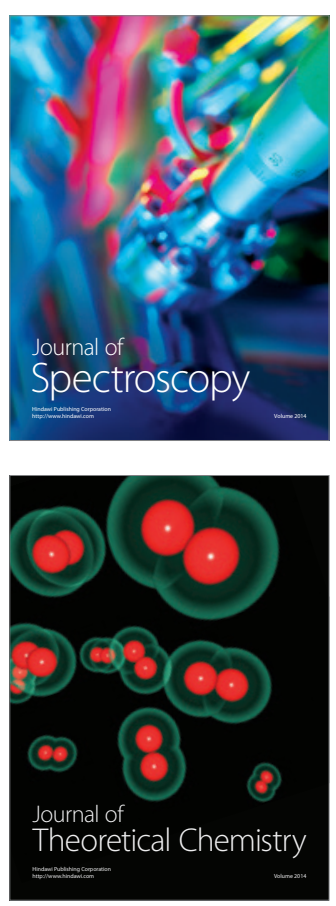
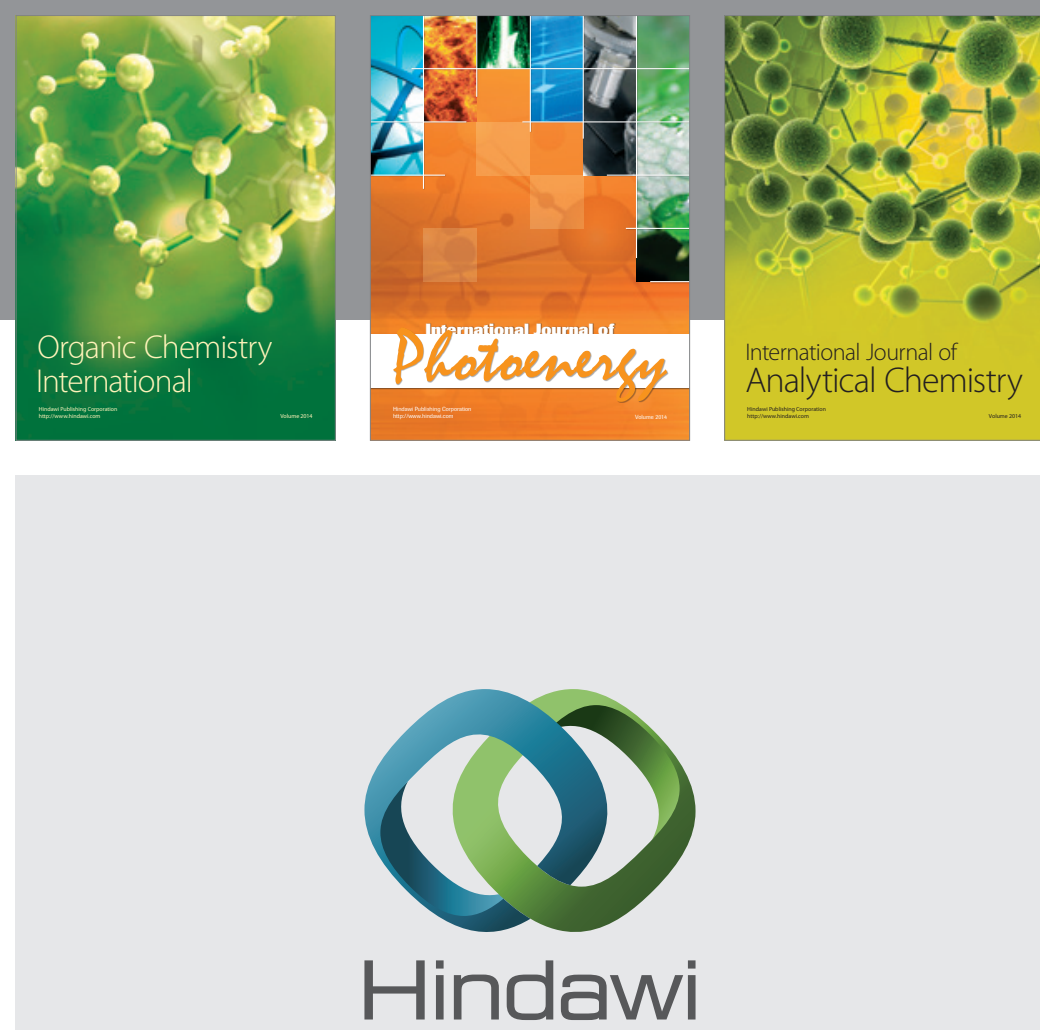

Submit your manuscripts at

http://www.hindawi.com
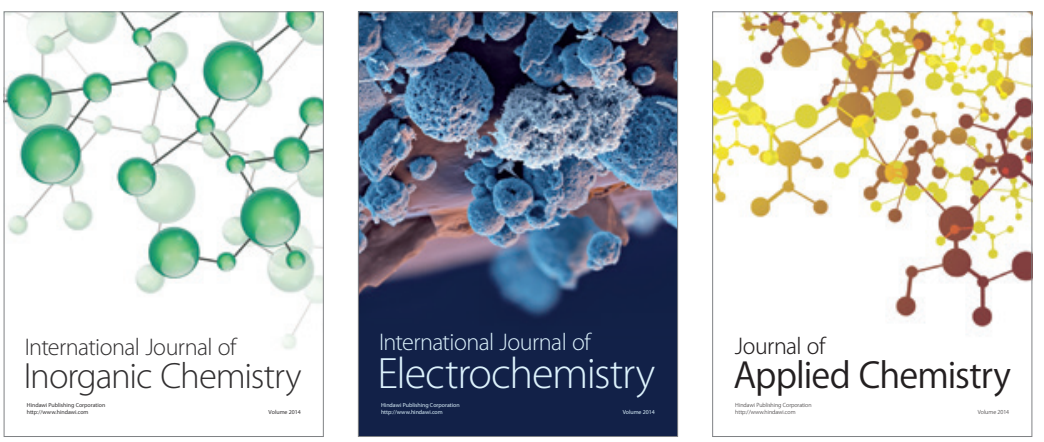

Journal of

Applied Chemistry
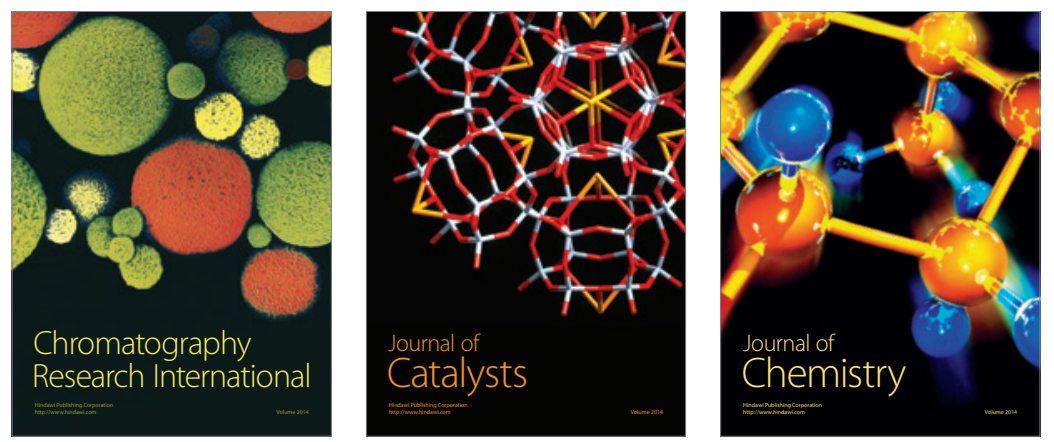
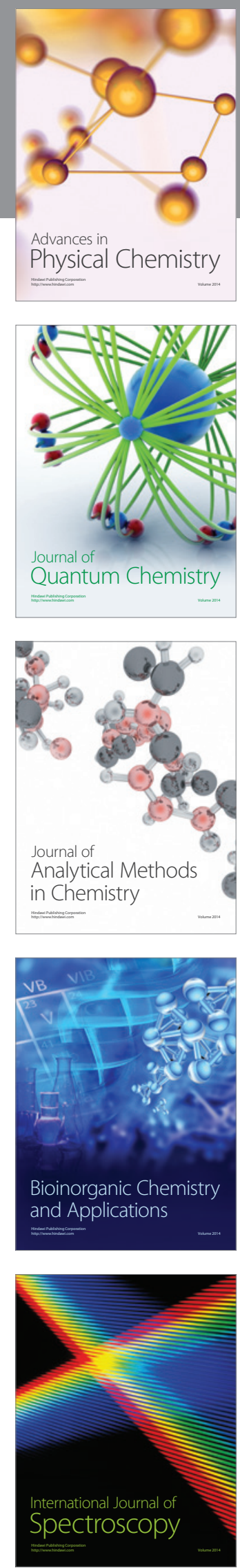